\title{
Impact of Technological, Organisational and Environmental Factors on Public Companies Ability to Utilise Big Data with Moderating Role of Organisational Culture: A Conceptual Model
}

\author{
Nura Muhammad Baba, Ahmad Suhaimi Baharudin, Shehu Hassan Ayagi, Ismail Basiru Sunusi, \\ Abubakar Muaz Ahmed
}

\begin{abstract}
The purpose of this research is to conduct a comparative study between Asean and European countries to find out the level of public company's ability to utilize big data. The research also aims to determine the role that organisational culture plays in the adoption of Big Data technologies. A survey in the form of questionnaire will be distributed through random sampling. Data will be collected from both Asean and $E U$ countries. Smart PLS will be used to test the hypothesis. Recommendations will be made to the Asean and EU government about the policies and strategies to implement so as to encourage more public organisation to adopt Big Data so as to increase their competitiveness and survival rate based on the result of the hypothesis.
\end{abstract}

Index Terms: Big Data; European Union; Public Companies; Organisation culture.

\section{INTRODUCTION}

With the advances in information technology (IT), increased competition, greater flexibility of products and more request from clients, firms are now required to operate their businesses in highly dynamic and complex environments. Similarly, the colossal increment of data generation due to digitisation, BDA will be significant for firms in both the public and private sectors to create value for effective decision-making, efficiency development and innovation. The world of data changes each day and every hour. New innovations and social networks such as twitter and WhatsApp have massively increased the amount of data and the possibilities available to organizations and people who want to collect and use it. The task and the opportunity are to make this new world of data useful and useable to improve people's lives. firms that survive and succeed in these market

Revised Manuscript Received on September 22, 2019.

Nura Muhammad Baba, Department of office Technology and Management, Kano State Polytechnic, Kano, Nigeria. Email: nabnurtrn@gmail.com

Ahmed Suhaimi Baharudin, School of Computer Science, Universiti Sains Malaysia, Penang, Malaysia. Email: asuhaimi@usm.my

Shehu Hassan Ayagi, department of Computer Science, Kano State Polytechnic, Kano, Nigeria. ashass2016@gmail.com

Abubakar Mu'azu Ahmed, Department of Computer science, Kaduna State University,Kaduna. abubakarmuaz11@gmail.com

Sanusi Ismail Basiru, Computer Science Department, Faculty of Computing, Federal University Dutse, Jigawa, Nigeria. Ibm_sunusi@yahoo.com conditions need to make decisions in a timely, efficient and appropriate manner [1].

However, many organisations are faced with the difficulties of data surplus where small subsets of large amounts of data are key to the overall evaluation of information [2]. For example, the International Data Corporation (IDC) reported that digital data growth was up by 48 per cent in 2012, with 90 per cent of information being unstructured [3]. As a result of this type of data complexity, many businesses are now faced with the challenged to comprehend and analyse the wide range of information involved [3]. Recently, Big Data Analytics (BDA) has emerged as a new technology to enhance the overall efficiency of management through productivity, performance, and better decision-making of the organizations in real-time. The importance of the abilities of Public Company (PC) to utilise the existing data is critical for the survival of $\mathrm{PC}$, since $\mathrm{PC}$ are competing not just locally but globally. However, as many business users lack access to the In order to increase efficiency, big firms have implemented IT systems in their business operations to gather, combine, access, and analyse massive amounts of data. One such analytical tool is Big Data technology. IDC expresses big data technologies as a new generation of technologies and architectures premeditated to excerpt value economically from very huge volumes of a diverse variety of data by empowering high-velocity capture, discovery, or analysis [4].

Due to increasing focus on big data and its capability to influence almost every sector of industry, it gives it the edge to be seen as new solution for enterprises. It has led to a titanic focus on exploring how organizations can harness information to gain a competitive advantage. It would be important to investigate, how organisations across the globe are putting it to use and in which way? Organisation had mostly launched initiatives to complement their analytical proficiencies. As technologies developed, and more companies involve analytics in handling data and figure out how to organize within this new analytics, it is now time for public companies to find easier time to reap the benefits associated with Big data. As servers and data centres become affordable and readily available that are delivered via cloud vendors, firms nowadays face less problem in 
terms of upfront investment; rather the challenges presents themselves as organizational and strategic of nature. Public companies can gain the benefits of the gigantic amounts of offline and online information to make intelligent, data-driven verdicts to nurture their trades. However, latest researches in management information lack emphasis on BDA adoption which is just one part of an implementation process, and it cannot ensure wide-scale usage and exploitation of BDA. Therefore, without wide-scale usage of BDA, its benefits cannot be fully understood.

While numerous parts of the economy have rushed to take up digital innovations and procedures, European industry across sectors and regardless of an organization's size should completely utilize digital opportunities if it is to be globally competitive. Traditional sectors such as construction, agro-food, textiles or steel are especially falling behind in their digital transformation. studies lately, have gauge that digitisation of products and services will add more than $€ 110$ billion of income for industry every year in Europe in the next five years. A few EU Member States have as of now dispatched techniques to bolster the digitisation of industry. However, an extensive methodology at European level is expected to maintain a strategic to avoid fragmented markets and to profit from digital advancements.

Recently, much world data has been exploded, and enterprises can capture, communicate, aggregate, store and analyze data source via high technologies. Thus, big data is intrusive in every sector and function of the global economy. The significance of big data implies much of modern economic activity, such as innovation and growth could take place with having proper data. Many researchers investigate big data volumes in order to find the business and economic possibilities. Besides, some researchers also examine if big data can create potential value for organisations and enterprises. Meanwhile, in industry, the newly emerged enterprises, big IT firms, and already new emerging consultant enterprises have begun to implement big data solutions for their businesses. Enterprises can get value from big data source when they manage to maintained capabilities to overcome difficulties such as data scalability, availability, and security. These values have been identified by [5], as ranging from Improving customer service and experience, retention, acquisition, cross-sell and upsell, competitive intelligence in benchmarking against their industry. However, only few studies on how firms can transfer value from big data to their businesses have been conducted. In spite of the fact that PC produce massive amount of data, lack of knowledge still exist to utilize the data effectively. Then again, competition among SMEs are on increase. Therefore, the project aims to research how PCs could use Big Data Analytics as a new strategy. This project will also offer a solution to overcame one of the most obstacle faced by PC's of recruiting the required skills personnel for delivering of IT innovation product like Big Data initiative, by providing various ways on how PC can access BDA analytic through cloud sourcing. Finally, researchers try to find some guidelines about how big data solutions can be a service business for consultancy companies. In an attempt to provide a conceptual framework for understanding the adoption of BDA among PC, the research questions that guide this study are: (1) what is the state of Big data adoption in PC and (2) What are the enabling factors affecting the adoption of Big data in PC. In conclusion, big data is regarded as a dynamic phenomenon rather than an emerging innovations. It has been a hot topic since it was viewed that enterprises can draw enormous potential value from big data, which is the principal competitiveness in these days business.

In 2014, Malaysia was ranked in 8 positions by Asia Cloud Readiness Index, which places Malaysia behind Australia, Hong Kong, Japan, New Zealand, Singapore and South Korea. ICT Development, International Connectivity, Data Protection Policy, and Government Prioritization were among the weakest indicators for Malaysia's readiness index. Likewise, Malaysia was ranked 60 out of 144 countries under the Technological Readiness pillar in the 2014/2015 World Economic Forum Global Competitiveness Index. This pillar measures the agility of an economy to adopt existing technologies to enhance the productivity of its industries.

However, if firms do not adopt big data, the potential or values that come with the data generated every day by the company will not be utilized. If adopted, it would enable organisation to identify new correlations that provide a return on investment through the creative use of existing information and to support the nation's economy to compete globally [6, 7]. Therefore, the more companies characterized themselves as data-driven, the better they performed on objective measures of financial and operational results. In particular, businesses that uses data-driven in decision making were $6 \%$ more profitable and 5\% more productive than their competitors [8]. This study will adopt TOE framework to study the phenomenon of interest.

\section{LiterATURE REVIEW AND HYPOTHESES DEVELOPMENT}

\section{A. Relationship between technological factors and extent of Big Data}

The influence of characteristics of innovations on the technology adoption has been studied quite extensively [9]. The first characteristic considers the benefits of available technologies to the firm, both internal and external, which might be helpful in improving organizational productivity [10]. The adoption decision can be largely driven by the perceived benefits of adopting an innovation in a specific organizational setting $[10,11]$. The second characteristic is the complexity of the new technology. The cost of migration, the technical expertise of existing IT staff members, and the degree of entrenchment with the new technology can act as barriers to the adoption process when the new technology is complex [12][120]. Firms delay in-house adoption of complex technology until they have obtained the technical know-how to implement and operate it successfully [12].

1) Relationship between Relative Advantage and extent of Big Data Check

The positive association of relative advantage with technology adoption is consistently revealed from prior studies $[11,13,14]$. For instance, relative advantage is an influencer of Internet adoption in emails, business 
homepage, and e-sales [14] and is a key factor across multiple innovation applications (i.e., online data access, email, EDI and Internet adoption) [11]. For example, considering Wang, Wang [15] investigated determinants of RFID adoption in the manufacturing industry, and they also found relative advantage has a positive effect on RFID adoption. Zhu and Kraemer [16], investigated determinants of post-adoption stages of innovation diffusion, using enterprise digital transformation as an example of innovation. Their results indicate relative advantage positively influence e-business usage. Besides this study, RFID (Radio Frequency Identification) technology as one of the agile technologies of last couple of decades, there are some studies on RFID adoption, one by [17] who investigated RFID adoption in the Taiwanese retail industry and found that relative advantage had a positive impact on RFID adoption. Ramdani, Kawalek [18], predicted SME's adoption of enterprise systems and suggest that the greater the perceived relative advantage of enterprise systems, the more likely they will be adopted by SMEs. [19], investigated adoption of EDI technology and suggested that relative advantage is a key factor within the technological context that can influence EDI adoption.

Following these studies, relative advantage would be an important factor to motivate organizations to adopt BDA technology. Decision makers will evaluate whether this technology has a relative advantage over conventional systems. Compared to conventional systems, BDA can help companies in several aspects, for example, in tracking, controlling, decision-making and innovating in real-time. If integrated with other backend systems, BDA can reduce the lead time, improve efficiency, and reduce labour costs [20]. However, small firms adopt technology only if they perceive a need for the technology to overcome a perceived performance gap or exploit a business opportunity [11]. Therefore, if firms believe that big data will enhance their business efficiency and effectively, they would be more inclined to continue to use it. Thus, the positive perception of the benefits of having big data analytics should lead to the greater possibility of its adoption. Therefore, this study hypothesizes that:

H1. Perceived relative advantage will have a positive impact on Big Data utilization.

\section{2) Relationship between Complexity of Data Mining}

Techniques and extent of Big Data

Complexity is among five factors that were proposed by Rogers [21] in the diffusion of innovation adoption. Many studies have found that complexity is a barrier to innovation adoption [22, 23]. Grover (1993) and [24], found that when customer-based inter-organizational systems are perceived as complex to adopt and/or use, they are less likely to be adopted. Mallat and Tuunainen (2008), suggest that perceived complexity inhibits merchant adoption of mobile payment systems. Ramamurthy et al. (2008), found that lower complexities in technology resulted in higher positive effects on the adoption of Data warehousing solutions. According to The Economist Intelligence Unit, the high complexity of Big data technology such as BI makes employees resist its adoption and continue to use traditional methods such as spreadsheet programs [25]. As such, Premkumar et al. (1994) suggest that the complexity of innovation is usually negatively related to its adoption [26]. Therefore, this study hypothesizes that:

H2 Complexity has a negative impact on Big Data Utilization

\section{B. Relationship between Organizational Context and extent of Big Data}

Based on the functional perspective of top managers [11], the capability perspective of an organization [27], and the technological resource perspective of an organization [16] management support, and IT staff capability are identified as important organizational factors.

\section{1) Relationship between Top Management Support} and extent of Big Data

Top management support for the adoption of technology is especially important for SMEs in which chief executive officers (CEOs) or equivalent have the final say on organizational IT strategy and investment. Premkumar and Roberts (1999) suggest that top management represents potential decision-makers in an organization [11]. They can create a positive environment to facilitate the adoption of new technologies by creating an appealing vision of how the adoption will benefit the firm, securing sufficient resources, and overcoming any member resistance to the change. For most of such businesses, the transition from the traditional in-house IT operation to the new big data is a strategic decision. If the executives understand big data and hold positive attitudes toward the innovation, they are likely to make decisions in favour of its adoption.

There is strong evidence that top management support leads to successful innovation of products [28], as well as successful implementation and assimilation of information systems [29-31]. Duan, Deng [32] provide a critical analysis of the adoption of e-market systems in Australian SMES, pointing out that factors such as top management support were the most important factors for SMEs who are ready to adopt an e-market for their e-business purposes. A survey of 325 manufacturing SMEs located in the central industrial sector of Iran found that the innovativeness of an owner-manager significantly impacted on their adoption of e-commerce [33]. Similarly, the study of Chang, Hung [22], found that an owner-managers' innovativeness is a significant determinant in ERP adoption for SMEs. Soliman and Janz [34] found that top management support significantly affects the adoption of Internet-based inter-organizational information systems while Teo, Lin [35] also found that top management support is positively associated with companies' adoption of e-procurement systems. Lin [36], noted that top management support is positively related to the likelihood of firms' adoption of electronic supply chain management systems. Chao and Chandra [37], conducted a survey with 217 small manufacturers and financial services organisations in the USA and found that the level of an owner's IT knowledge is a key predictor of IT strategic alignment, as well as the adoption of IT. Thong, Yap [31] claimed that owner-managers who have more IT knowledge will be more likely to be innovative. An interesting aspect of this finding is that although owner-managers' IT knowledge can increase the chances of IT adoption in organisations, advanced IT applications including big data 
have received quite low rates of adoption among smaller firms due to the critical constraints of resources in such firms. Therefore, this study hypothesizes that:

H3 Top management support will have a positive impact on Big Data utilization.

\section{2) Relationship between IT Staff Capability and \\ Extent of Big Data}

The technological knowledge of an organization is part of the organizational technology context that promotes (or inhibits) adoption [16] and has a positive relationship with the likelihood of technology adoption decision. It can be extended to non-IT professionals, a group that has been shown to be more likely to support and accept new technologies when they have a relatively high level of IT knowledge about technological innovations. Lawson, Alcock [38], also mention that lack of IT expertise in a firm is one of the barriers to e-commerce involvement and has an effect on decisions about doing business online. Neidleman [39] believed that small European organizations failed because they lacked knowledge of information systems. Because of the obstacle lack of skill and technical knowledge required in the development process, many organizations delay innovation adoption and tend to wait until they have sufficient skills. Thus, if employees in SMEs have more knowledge of information systems, then they will be more likely to adopt the information systems.

As Ettlie [40] explained, staff must have some knowledge of IT innovation in order to use more innovative IT. Thong, Yap [31] believed that organizations have different levels of information need in various sections, and there is more need to implement IS in information intensified sectors. Porter and Millar [138] suggested that the greater the information intensity, the greater the potential for the use of information systems. Haber and Reichel [41] and Thong [42] believed that greater information intensity in SMEs would lead to the senior executives believing that IS is a major competitive tool, and this would increase IS adoption. Typically, lack of staff IT knowledge led to existing information technology not being used effectively Lawson, Alcock [38]. Thereby, SMEs employee IS knowledge would have great influence on the extent to which an organization is capable of successfully adopting a big data. This suggests that when SMEs are planning to adopt Big data they would then consider the level of employee IT-related knowledge. Therefore, this study hypothesizes that:

H4 IT staff capability will have a positive impact on Big Data utilization.

\section{Relationship between Environmental Context and Extent of Big Data}

Hello Several studies in developing countries indicate that factors related to the environmental context play a more significant role than factors related to the technological and organizational contexts [33]. Other useful theories that are considered in our framework to explain the influence of factors within the environmental contexts are Competitor pressure and Government support.

\section{1) Relationship between Competitor Pressure and Extent of Big Data}

The relationship between IT innovations and competition, or environment uncertainty, has been explored in several previous IT adoption studies, with virtually all findings supporting this relationship [10, 16, 27, 42]. Competitive pressure has been widely recognized and empirically supported in the diffusion of information technologies literature as one of the major factors in the environmental context of the TOE model [16, 24, 43]. The classic five-force competitive model indicates that competitive pressure is an important external driver to initiate the deployment of IOS (inter-organizational innovation) among trading partners [44]. Adoption of a new innovation might help a firm to gain and sustain competitive advantages over its competitors [45]. Similarly, it has been explained that innovations allow firms to achieve an edge in competitive environments [10]. Zhu, Kraemer [27], found that companies facing higher levels of competitive pressure are more likely to adopt electronic business. Wang and Cheung [46] propose that competitive pressure is positively related to travel agencies' adoption of e-business . Oliveira and Martins [47], found that competitive pressure is a positive predictor of e-business adoption for both the telecommunications industry and the tourism industry. Similarly, Lin [36], found that competitive pressure is positively related to the likelihood of firms' adoption of electronic supply chain management systems. If more and more competitors begin to adopt Big data to enjoy its benefits, the decision makers in an organization are likely to feel the pressure to do the same in order to retain competitive advantage. Therefore, this study hypothesizes that:

H5: Competition Pressure will have a positive impact on Big Data utilization.

\section{2) Relationship between Government Support and Extent of Big Data}

Governement support is one of the critical factors influencing innovation diffusion [48, 49]. Government support refers to the support given by a government authority to encourage the assimilation of IT innovation by firms [49]. The impact of existing laws and regulations can be critical in the adoption of new technologies. Government regulations can encourage or discourage businesses from adopting big data. For example, legislators in the United States and the European Union member states have specific mandates to protect organizational data. When a government requires businesses to comply with big data standards and protocols, firms will be more willing to adopt big data computing. According to NIPA (2015) government policy and support related to open data, clouding computing, and industrial promotion may stimulate the adoption of big data $[50,51]$. Government can create a favourable environment and provide impetus for technology adoption [52]. Likewise, government plays a major role in providing the required national ICT infrastructure such as reliable Internet connection with reasonable speed and appropriate technology standards [53]. For example, Zhu, Kraemer [49] investigates the assimilation of e-business and finds that governments can encourage e-business legislation by supportive regulations and policies. Another study by [54] also discovered that the assimilation process of Internet technologies in China and concludes that Chinese companies have the highest 
concern for the regulatory environment in which they and their business reside. Therefore, this study hypothesizes that:

H6 Government support will have a positive impact on Big Data utilization.

world

\section{The Mediating Effect of Extent of BDU on the Relationship between TOE factors and Performance}

Based on the research conducted by Economist Intelligence Unit (2012) comprising of 607 executives from across the globe, the results show that for processes where Big Data analytics has been applied, on average, they have seen a $26 \%$ improvement in performance over the past three years, and they expect it will improve by $41 \%$ over the next three, the survey also report that firms that emphasise decision-making based on data and analytics have performed 5-6\% better-as measured by output and performance - than firms that rely on intuition and experience for decision-making [55]. Similarly, Established organizations have attained considerably superior business payback from BI [56]. Therefore, this study hypothesizes that:

H7 extent of BDU Mediates the Relationship between TOE Factors and Performance

\section{E. The Moderating Effect of OC on the Relationship between Extent BDU and Performance.}

Schein [57] defined organizational culture as a pattern of basic assumptions that are invented, discovered, or developed by a given group as it learns to cope with problems of external adaptation and internal integration and that have worked well enough to be considered valid and, therefore, taught to new members as the correct way to perceive, think, and feel in reference to those problems. Various studies also suggest that organizational culture plays an important role in technology and innovation adoption. For instance, the diffusion literature asserts that organizational culture is an important organizational factor for technology adoption [9, 58]. IS literature also echoes this assertion [59, 60]. Peters, Waterman [61], have suggested that organisational culture can exert considerable influence in organisations particularly in areas such as performance and commitment. It has an influence on the degree where innovation and creativity are stimulated in an organization $[14,62]$. Therefore, this study hypothesizes that:

H8 Organizational culture moderates the relationship between extent of big data utilization and performance

\section{1) The Moderating Effect of Region (Asia \& EU) on the Relationship between Extent of BDU and Performance}

Past empirical studies based on different geographical locations have evidenced that different management structures and environments would have different impacts on company performance be it financially or non-financially [63]. Therefore, this study hypothesizes that:

H9 Region (Asean \& EU) moderates the relationship between extent of big data utilization and performance

\section{F. Theoretical Framework and Hypotheses}

This study proposed the research model as shown below, where we have the dependent variable, the independent variable, the mediator and moderator variable. The dependant variable performance, the IV are Perceived Relative Advantage (PRA), Complexity of Data Mining Techniques (CDMT), Management Support (MS), IT Staff Capabilities (ITSC), Competitive Pressure (CP), Government Support (GS), Extent of Big of Data (Ex BDU) as mediator variable and Organisational Culture (OC) and Region ( both EU and Asean) as moderator variable.

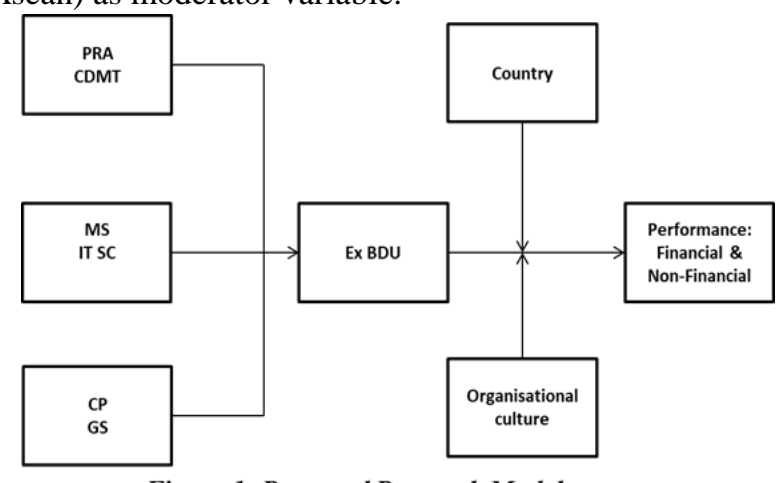

Figure 1: Proposed Research Model

\section{RESEARCH METHODOLOGY}

The research model includes 11 constructs: technology characteristics which contain perceive relative advantage and complexity of data mining techniques, organization characteristics contain management support ad IT staff capability, and environment characteristics that have competitive pressure and Government support, performance as dependent variable, extent of big data as the mediator variable and organisational culture and Region (Asia \& EU) as the moderator variable

To evaluate the theoretical constructs, a survey will be conducted in two regions (Asia \& EU countries). A questionnaire was developed by an expert panel composed of experienced researchers in the field of Information Systems. The questionnaire items were based on published literature (see table 1). Seven points Likert scale on an interval level ranging from "strongly disagree" to "strongly agree" will be used. The questionnaire will be administered in the languages of the both region (Asia \& EU) of study. The questionnaire will be reviewed by a group of established academic IS researchers and three language experts. A pilot study will be conducted among 20 firms so as to provide evidence that the scales are reliable, valid, and have translation equivalence.

The research will make use of database available from Entrepreneur-sme.asia and ec.europa.eu to get list of SMEs for both regions. The study will identify and make use of specific SME industry sector. This because the management literature had shown that an imprecise result will be obtained if more than one sector is involve in the same study.

The items of the survey include a range of questions to measure the IV, DV, mediator and moderator variable. The population of this study will comprise of both SMEs from Asean and EU countries. This study will make use of simple random sampling because a every sample in the population has equal chance of being chosen. The research will utilised mail, electronic and self-administered questionnaire.

A Quantitative research will be used. It was chosen because quantitative approaches offer a

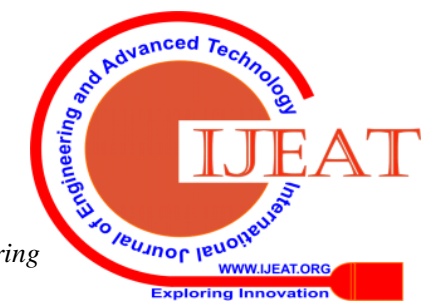


primary connection between empirical observation and the mathematical expression of quantitative relationships. Quantitative research has been utilised in a number of studies to measure and test hypotheses based on an empirical examination of dependent and independent variables employing statistical techniques [64]. Exploratory and confirmatory factor analyses will be used to assess the convergent and discriminant validity of the survey instrument. The reliability of the survey instrument will be evaluated using Cronbach's alpha and composite reliability. The collected data will be analysed using Structural Equation Modelling (SEM) and (Partial Least Square) PLS based on Smart PLS software in order to investigate the relationship between the variables.

\section{CONCLUSION}

The study aim to conduct a comparative study between the Asean and EU countries to find the level of public companies abilities to utilize big data. A quantitative survey will be used to test the study hypotheses using structural equation modelling technique. Data will be collected from both Asean and EU public companies. The findings from the analysis of the study will be used to make recommendations to both the Asean and EU government about the policies and strategies to implement to encourage more public firms to adopt Big Data to increase their competitiveness and survival rate.

1. of a paper is to introduce a new measurement technique. Authors should expect to be challenged by reviewers if the results are not supported by adequate data and critical details.

\section{ACKNOWLEDGMENT}

This research is supported by Universiti Sains Malaysia through the USM Bridging Grant 2017 [A/C Number: 304.PKOMP.6316001].

\section{REFERENCES}

[1] Habjan, A., A. Popovic, and S. ENGLAND, Achieving business process change with improved business intelligence systems: a case of Slovenian company. WSEAS TRANSACTIONS on BUSINESS and ECONOMICS, 2007(7).

[2] Arnott, D. and G. Pervan, A critical analysis of decision support systems research. Journal of information technology, 2005. 20(2): p 67-87.

[3] Gens, F., Top 10 predictions-IDC predictions 2012: Competing for 2020. International Data Corporation, 2011.

[4] Vesset, D., et al., Worldwide big data technology and services

[5] Ramdas, S.H.a.T., Big Data in Malaysia: Emerging Sector Profile 2014, Creative Commons Attribution-NonCommercial-NoDerivatives 4.0

[6] Schwab, K. and X. Sala-i-Martín. The global competitiveness report 2013-2014: Full data edition. 2016. World Economic Forum.

[7] Schwab, K. The Global Competitiveness Report 2017 2018. 2017. World Economic Forum.

[8] McAfee, A., et al., Big data: the management revolution. Harvard business review, 2012. 90(10): p. 60-68.

[9] Tornatzky, L.G., M. Fleischer, and A.K. Chakrabarti, Processes of

[10] Lippert, S.K. and C. Govindarajulu, Technological, organizational, and environmental antecedents to web services adoption. Communications of the IIMA, 2006. 6(1): p. 14.

[11] Premkumar, G. and M. Roberts, Adoption of new information technologies in rural small businesses. Omega, 1999. 27(4): p. 467-484. 2012-2015 forecast. IDC Report, 2012. 233485. technological innovation. 1990: Lexington books.

[12] Attewell, P., Technology diffusion and organizational learning: The case of business computing. Organization science, 1992. 3(1): p. 1-19.

[13] Shah Alam, S., et al., Factors affecting e-commerce adoption in the electronic manufacturing companies in Malaysia. Internationa Journal of Commerce and Management, 2008. 17(1/2): p. 125-139.

[14] Lee, J., Discriminant analysis of technology adoption behavior: a case of internet technologies in small businesses. Journal of computer information systems, 2004. 44(4): p. 57-66

[15] Wang, Y.-M., Y.-S. Wang, and Y.-F. Yang, Understanding the determinants of RFID adoption in the manufacturing industry. Technological forecasting and social change, 2010. 77(5): p. 803-815.

[16] Zhu, K. and K.L. Kraemer, Post-adoption variations in usage and value of e-business by organizations: cross-country evidence from the retail industry. Information systems research, 2005. 16(1): p. 61-84.

[17] Tsai, M.-C., W. Lee, and H.-C. Wu, Determinants of RFID adoption intention: Evidence from Taiwanese retail chains. Information \& Management, 2010. 47(5-6): p. 255-261.

[18] Ramdani, B., P. Kawalek, and O. Lorenzo, Predicting SMEs' adoption of enterprise systems. Journal of enterprise information management, 2009. 22(1/2): p. 10-24.

[19] Kuan, K.K. and P.Y. Chau, A perception-based model for EDI adoption in small businesses using a technology-organization-environment framework. Information \& management, 2001. 38(8): p. 507-521.

[20] Agrawal, K.P. Investigating the determinants of Big Data Analytics (BDA) adoption in emerging economies. in Academy of Management Proceedings. 2015. Academy of Management Briarcliff Manor, NY 10510

[21] Rogers, E.M., Diffusion of innovations. 2010: Simon and Schuster.

[22] Chang, S.-I., et al., Critical factors of ERP adoption for small-and medium-sized enterprises: An empirical study, in International Comparisons of Information Communication Technologies: Advancing Applications. 2012, IGI Global. p. 205-230.

[23] Hung, S.-Y., S.-I. Chang, and P.-J. Lee, Critical factors of ERP adoption for small-and medium-sized enterprises: An empirical study. PACIS 2004 Proceedings, 2004: p. 57.

[24] Cooper, R.B. and R.W. Zmud, Information technology implementation research: a technological diffusion approach. Management science, 1990. 36(2): p. 123-139.

[25] Unit, E.I., Business Intelligence: Putting Enterprise Data to Work. EIU Oracle Sponsored Study, 2007.

[26] Premkumar, G. and K. Ramamurthy, The role of interorganizational and organizational factors on the decision mode for adoption of interorganizational systems. Decision sciences, 1995. 26(3): p 303-336.

[27] Zhu, K., K. Kraemer, and S. Xu, Electronic business adoption by European firms: a cross-country assessment of the facilitators and inhibitors. European Journal of Information Systems, 2003. 12(4): p. 251-268.

[28] Maidique, M.A. and B.J. Zirger, A study of success and failure in product innovation: the case of the US electronics industry. IEEE Transactions on engineering management, 1984(4): p. 192-203.

[29] Chatterjee, D., R. Grewal, and V. Sambamurthy, Shaping up for e-commerce: institutional enablers of the organizational assimilation of web technologies. MIS quarterly, 2002: p. 65-89.

[30] Liang, H., et al., Assimilation of enterprise systems: the effect of institutional pressures and the mediating role of top management. MIS quarterly, 2007: p. 59-87.

[31] Thong, J.Y., C.-S. Yap, and K. Raman, Top management support, external expertise and information systems implementation in smal businesses. Information systems research, 1996. 7(2): p. 248-267.

[32] Duan, X., H. Deng, and B. Corbitt, Evaluating the critical determinants for adopting e-market in Australian small-and-medium sized enterprises. Management Research Review, 2012. 35(3/4): p. 289-308.

[33] Ghobakhloo, M., D. Arias-Aranda, and J. Benitez-Amado, Adoption of e-commerce applications in SMEs. Industrial Management \& Data Systems, 2011. 111(8): p. 1238-1269.

[34] Soliman, K.S. and B.D. Janz, An exploratory study to identify the critical factors affecting the decision to establish Internet-based interorganizational information systems. Information \& Management, 2004. 41(6): p. 697-706.

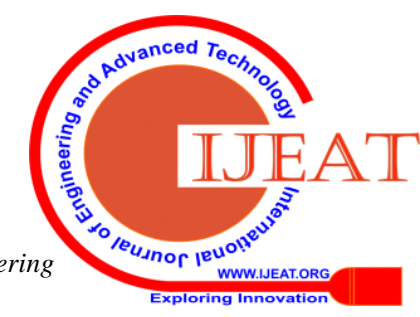


[35] Teo, T.S., S. Lin, and K.-h. Lai, Adopters and non-adopters of e-procurement in Singapore: An empirical study. Omega, 2009. 37(5): p. $972-987$.

[36] Lin, H.-F., Understanding the determinants of electronic supply chain management system adoption: Using the technology-organization-environment framework. Technological Forecasting and Social Change, 2014. 86: p. 80-92.

[37] Chao, C.-A. and A. Chandra, Impact of owner's knowledge of information technology (IT) on strategic alignment and IT adoption in US small firms. Journal of Small Business and Enterprise Development, 2012. 19(1): p. 114-131.

[38] Lawson, R., et al., Factors affecting adoption of electronic commerce technologies by SMEs: an Australian study. Journal of small business and enterprise development, 2003. 10(3): p. 265-276.

[39] Neidleman, L., Computer usage by small and medium sized European firms: an empirical study. Information \& Management, 1979. 2(2): p. 67-77.

[40] Ettlie, J.E., What makes a manufacturing firm innovative?

[41] Academy of Management Perspectives, 1990. 4(4): p. 7-20.

[42] Haber, S. and A. Reichel, Identifying performance measures of small ventures - the case of the tourism industry. Journal of small business management, 2005. 43(3): p. 257-286.

[43] Thong, J.Y., An integrated model of information systems adoption in small businesses. Journal of management information systems, 1999. 15(4): p. 187-214.

[44] Belassi, W., A.Z. Kondra, and O.I. Tukel, New product development projects: The effects of organizational culture. Project Management Journal, 2007. 38(4): p. 12-24.

[45] Porter, M.E., Competitive strategy: Techniques for analyzing industries and competitors. 2008: Simon and Schuster.

[46] Porter, M.E. and V.E. Millar, How information gives you competitive advantage. 1985, Harvard Business Review Reprint Service.

[47] agencies: prime candidates for mobile e-business. International Journal of Electronic Commerce, 2004. 8(3): p. 43-63.

[48] Oliveira, T. and M.F. Martins, Firms patterns of e-business adoption: evidence for the European Union-27. Electronic Journal of Information Systems Evaluation, 2010. 13(1): p. 47.

[49] Bouchikhi, H., A constructivist framework for understanding entrepreneurship performance. Organization studies, 1993. 14(4): p. 549-570.

[50] Zhu, K., K.L. Kraemer, and S. Xu, The process of innovation assimilation by firms in different countries: a technology diffusion perspective on e-business. Management science, 2006. 52(10): p. 1557-1576.

[51] Park, J.-H., M.-K. Kim, and J.-H. Paik, The Factors of Technology, Organization and Environment Influencing the Adoption and Usage of Big Data in Korean Firms. 2015.

[52] NIPA. National IT Industry Promotion Agency: Technology roadmap for big data, 20152015 [cited 201523 June ]; Available from: https://www.nipa.kr/eng/main.it.

[53] Gibbs, J.L. and K.L. Kraemer, A cross- country investigation of the determinants of scope of e- commerce use: an institutional approach. Electronic markets, 2004. 14(2): p. 124-137.

[54] Wahid, F., Using the technology adoption model to analyze internet adoption and use among men and women in Indonesia. The Electronic Journal of Information Systems in Developing Countries, 2007. 32(1): p. 1-8.

[55] Chau, P.Y., F. Lai, and D. Li, What factors drive the assimilation of internet technologies in China? Communications of the ACM, 2008. 51(9): p. 132-135.

[56] Unit, E.I., The deciding factor: Big data \& decision making. Capgemini Reports, 2012: p. 1-24.

[57] Raber, D., F. Wortmann, and R. Winter. Situational business intelligence maturity models: An exploratory analysis. in 2013 46th Hawaii International Conference on System Sciences. 2013. IEEE.

[58] Schein, E.H., Organizational culture and leadership. Vol. 2. 2010: John Wiley \& Sons.

[59] Rogers, E.M., Diffusion of Innovations. Knowledge and Innovation Management, 2007: p. 37.

[60] Denison, D.R., S. Haaland, and P. Goelzer, Corporate culture and organizational effectiveness: Is Asia different from the rest of the world? Organizational dynamics, 2004. 33(1): p. 98-109.

[61] Orlikowski, W.J., CASE tools as organizational change: Investigating incremental and radical changes in systems development. MIS quarterly, 1993: p. 309-340.

[62] Peters, T.J., R.H. Waterman, and I. Jones, In search of excellence: Lessons from America's best-run companies. 1982.
[63] Hwang, H.-G., et al., Critical factors influencing the adoption of data warehouse technology: a study of the banking industry in Taiwan. Decision Support Systems, 2004. 37(1): p. 1-21.

[64] Jackling, B. and S. Johl, Board structure and firm performance: Evidence from India's top companies. Corporate Governance: An International Review, 2009. 17(4): p. 492-509.

[65] Bernard, H.R. and H.R. Bernard, Social research methods: Qualitative and quantitative approaches. 2013: Sage.

\section{AUTHORS PROFILE}

Nura Muhammad Baba, Department of office Technology and Management, Kano State Polytechnic, Kano, Nigeria. Email: nabnurtrn@gmail.com

Ahmed Suhaimi Baharudin, School of Computer Science, Universiti Sains Malaysia, Penang, Malaysia. Email: asuhaimi@usm.my

Shehu Hassan Ayagi, department of Computer Science, Kano State Polytechnic, Kano, Nigeria. ashass2016@gmail.com

Abubakar Mu'azu Ahmed, Department of Computer science, Kaduna State University,Kaduna. abubakarmuaz11@gmail.com

Sanusi Ismail Basiru, Computer Science Department, Faculty of Computing, Federal University Dutse, Jigawa, Nigeria. Ibm_sunusi@yahoo.com 